\title{
Decision support water management a case study
}

\author{
S. VenkatCharyulu ${ }^{1}$, and Dr. G.K.Viswanadh ${ }^{2}$ \\ ${ }^{1}$ Assistant professor, Gokaraju RangaRaju Institute of Engineering \& Technology, Hyderabad, India and Research scholar, \\ (Department of Civil Engineering, JNTUH, Kukatpally, Hyderabad, India ,) \\ ${ }^{2}$ Professor of Civil Engineering and Director, UGC-HRDC JNTUH, Kukatpally, Hyderabad, India,
}

\begin{abstract}
Decision support water. Management (DSWM) is an approach to water development and water management, for the best water management framework. In the field of water management for watter storage, and preservation of land is very important criteria which is linked with various communities involvement, economical issues and environmental issues. DSWM. water resources needed extensive advance technology with reliable activity. For this purpose in this paper it need to analyse the various volume, quality and quantity parameters and other enhance model usage are adopted to maintain the effective water resource management.. Parameters collect the management tools for efficient management of water resources under varied local situations. In This paper discussed some of the analytical management techniques and development decision support water management system as a framework for decision makers to have reliable decisions for water management practises. This paper includes overall DSWM functions and their highlights to achieve the effective water management.
\end{abstract}

\section{Introduction}

Main principles involved in the water management are integrated, sustainable, reuse and recycle as serious concerns issues for the development. In India combining river basin management has developing day by day concluding all environmental and hydrological parameters. The study area has taken as Godhavari sub basin in Telangana state, India. This area is completely flowing with Godavari River. And finally join in the bay of Bengal. The main purpose of the water managing in this area has considered as various components and process the different steps to obtain the final results. The results obtain from the various components will be giving an idea to the water manager to have the decisions. Integrated water management was evolved from UN 21 as agenda . Many countries are also showing developments of integrated water management as national and international agenda. In world sumit sustainable and development held in 2002 at john-Burg initiated many important water management activities[6].

This paper presents the description of various components of study area and results from the study area. The flow diagram of the work process is followed and Shown in the Figure. 2.

The water shed has many types of species including the endangered speics.( NRSC 2008) [5]The population of the specis decling due to series of dams construction (Zimmerman 2006). Unique form of flood plain vegetation will promoted by $\mathrm{g}$ eographical formation.(Apse et.al2008). The study area is lift irrigation situated in the mahadev pur mandal and district of jayashankar bhoopolpally. T.S, ,India This study area is benefit to $18,211 \mathrm{Ha}$ of irrigation land area can supply from tanks water storage capacity of 4.5 TMC. From this area drinking water purpose supply of 0.3 TMC nearby village. Because of this project benefits to 63 villages. Project work helpful to 4 mandals exiting near by area. The Construction of drinking water supply involves canal intake, pumping house, project work is need drinking water reons, pressure conduits and canals. This water supply project is lifting water from pump house through the pressure main pipelines finally the water supplied to water storage tanks through underground pipe line system. Canals are 1 constructed to utilize the natural 
gravity pressure under which all existing tanks to supply the water to the irrigation fields. This is a flagship project for the T.S(Telangana state) . India and finally constructed. (CDM) as a mechanism for management practice for sustainable water resources management. [7]

World recognized significance for the eco friendly and sustainable difficulties and suggested action for drinking water supply included sanitation disposal as on better frameworks for IWRM and water governance at all levels to solve these challenges (WEHAB Working Group, 2002) . The IRBM exiting in India, where the 8th India Plan (8MP, 2001-2005) and the. Different sizes, including a river basin scale, IRBM (Integrated River Basin Management) can be a subset of IWRM .In which a river basin is a geographical entity with definite limits which incorporates all hydrological processes and their ecosystems and which intersects with political and administrative divisions.

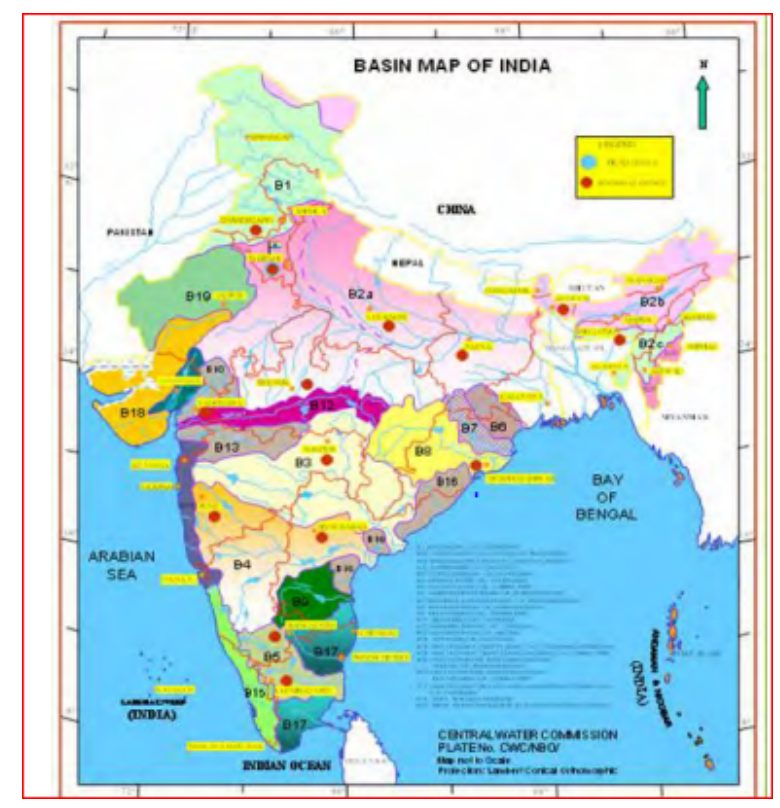

Fig1 Basin map of India (source cwc (pune))

22 number of major rivers with many tributaries embodiment in the river network of India. Some of the rivers finally joining in tothe sea near Bengal state India; Few rivers, whose tributaries from the starting western part of the Indian country and flows towards the Himachal Pradesh state and finally reaches into the Sea (Arabia). Northern Indian parts of the Aravalli hill range and the parts of the Desert which has inland drainage. Fig2.. Shows the Indian
River basins. Water management need more attention and action. IWRM is the method to tackle them costeffectively and sustainably (Zaharaton, 2004). The DSWM is Conflicts in water resource management, such as water rights allocation, flood management, pollution control and preservation of the environment, must be handled by decision makers to have dialogue among them to have water management.. In June 1998, the Federal Government formed a National Water Resources Council (NWRC) or Majlis Sumber Air Negara to address these challenges with the objective of making the water management by different States more effective and coherent. The NWRC is responsible for governing water resource policies and general management in India and develops a national water strategy for long-term sustainability. In theory, the implementation in the country of the IRBM is seen by the NWRC and the Federal Government as a step towards more effective water management in India. In order to ensure effective use of this diminishing resource, [7] IWRM will be used in planning, development and management of water resources, and assist the execution of various types of projects, precluding inter-basin and inter-state water transfers.( Rahmah Elfithri et.al .2012).

\section{Need of DSWM water management}

In the study area is concern to land and water management at River upstream and downstream side .In the Thework flow process as follows process initiated with the hydrological data studies and collection of various parameters . Physical catchment area of the map has taken from GIS map

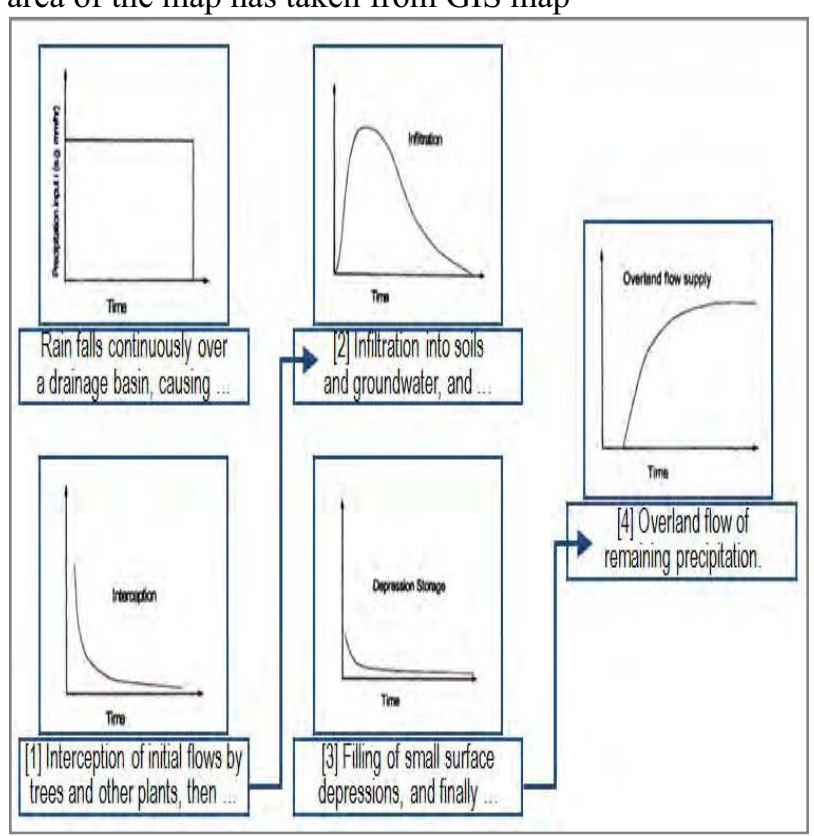


Fig 2 showing the hydrological process (CWC report) rive Basin ( cwc, pune).

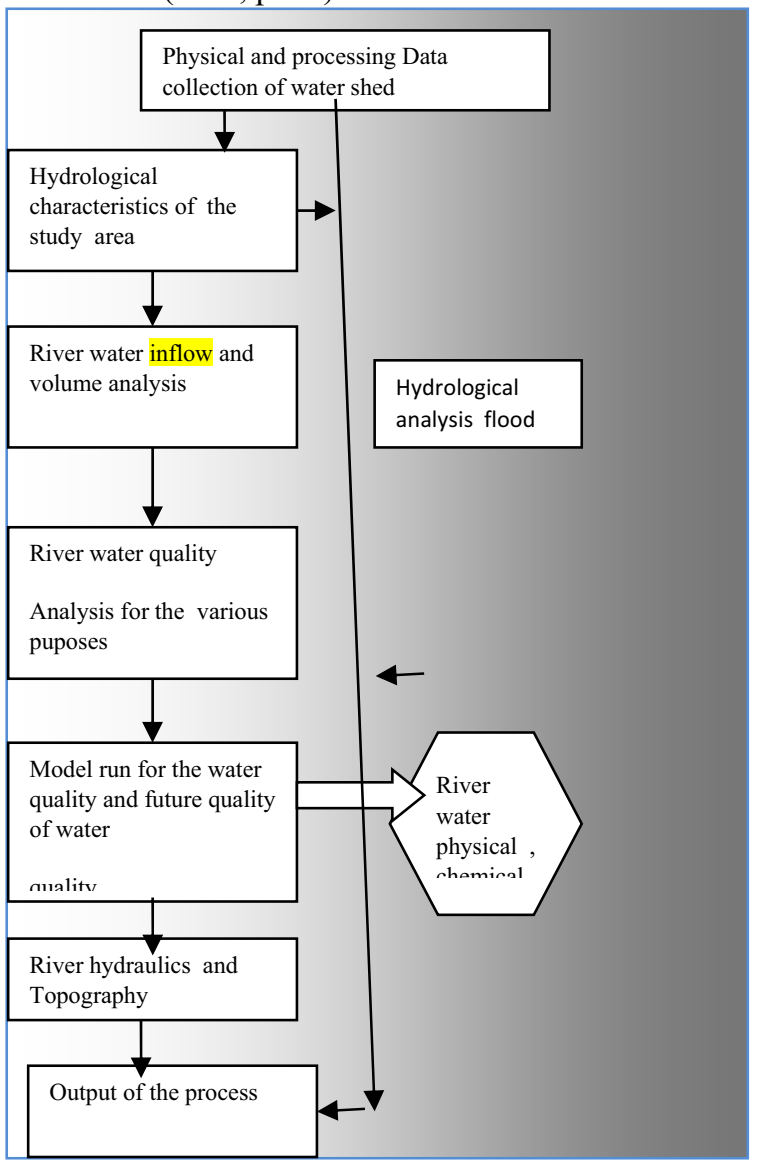

Fig.3 output for the Decision process

Figure2 shows hypothetical situation for the hydrological process in the basin with different phases .such as rain fall, interception ' and time graph, infiltration continuously over the by the plants and trees graph, filling of small surfaces depressions, and overland flows graphs are related hydrological process. The rain fall over the basin has gone through this phases and contribute some volume to the river and its tributaries . the flow carried by the river has to find out quality and quantity. The water volume supplying for the various need is another important aspect of the sustainable management. The rain fall over the basin is divide in to surface flow and ground water flow. The water over the basin are flows in to the various drains and finally reaches to the farthest point of the outlet of the water shed .

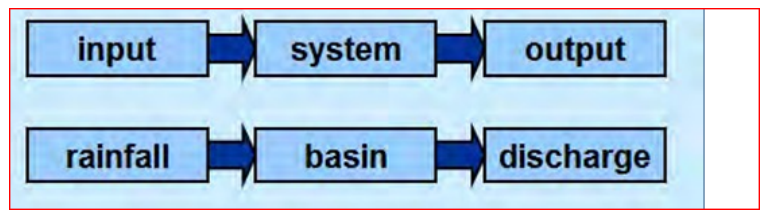

Fig.4 Rain fall process and syttem input and output

\section{Study Area}

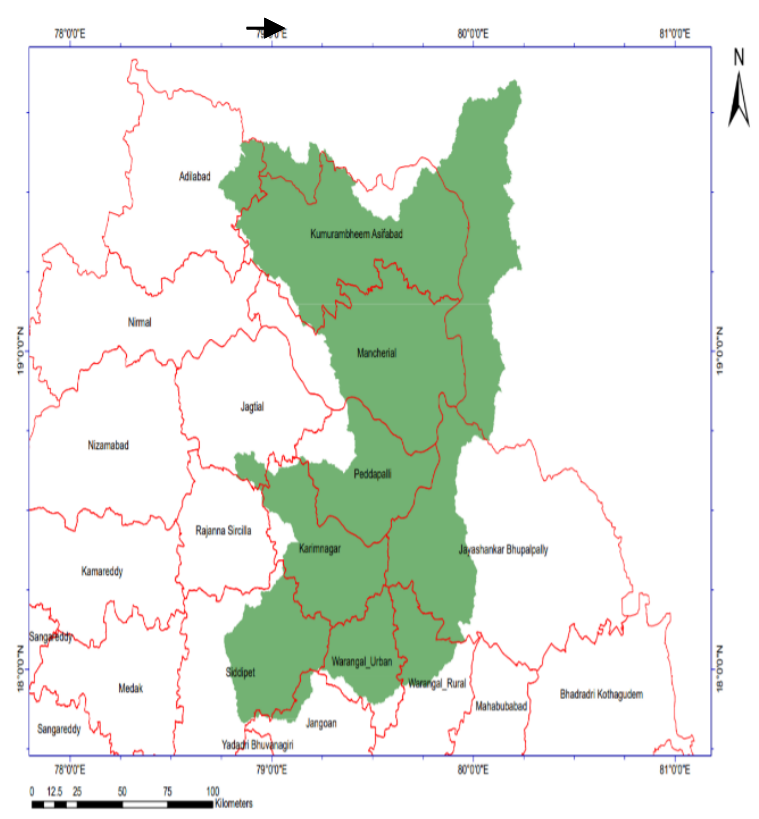

Fig.5. Water shed area of the Godhavari basin

As envisioned in its definition, the main objective of DSWM is to maximize the economic and social benefits derived from water resources. This aspect can be further divided into different components as follows

a. Water Supply for drinking and sanitation

b. Industrial needs and Sustainability

c. Irrigation and Animals survaival

d. Water Quality of the river

e. Hydropower Generation

f. Flood Damage Reduction

Several engineering solutions may satisfy "purposes of development": choice between solutions based on how well they achieve the objectives. Enumerates the various purposes which enable achieving the different types of objectives:

\section{Objectives of the study area}


1. Water shed area delineation

2. Watershed characteristics and Hydrological

Parameters influence in the water shed

3. Volume of the water for given period

4. Quality of the water

The processing the above objective management of water resources, without any problems. Certainly, economic values may be consider for the encourage desirable result. In developing nations, the economic strategy based on the notion that those application of an economic strategy, employing economic or market-based elute or utilise a resource should pay has effectively been employed to solve numerous environmental concerns, including water management. Cost-effectiveness is the main advantage of the economic or market approach. [8] It will enable for faster water management objectives and decrease compliance and administrative expenses Economic efficiency, fairness and environmental sustainability are the ideals to be embraced. A structural framework consisting of managerial instruments, the environment and institutional set-up must also be developed. [9] This paper covers some of the essential management techniques, including the development of collaborative decision-making as a framework for sustainable water management practises. This paper also highlights the relevance of public involvement and the function of the EIA procedure in water resource management. [10] ( Rahmah Elfithri, Rawshan Ara Begum et.al .2012).

\section{Method}

The DSWM is the multi-disciplinary approach of water management in the study area. It has considered the watershed area; hydrological data has been taken from multiple sources and concern departments. Most data has been generated from the related soft ware analysis for the effective management. It empowers a comprehensive methodology for resolving issues identified with water assets in a basin[15].The significant disciplines for DSWM are as under:

Hydrology : concern about evaluating normal dispersion of water in existence (appraisal of water assets)

Hydrulics : Distribution of water management

Environmental approach : evaluating water quality in existence, a water treatment measures whereby this can be changed to accord with water quality guidelines Factors portraying contributions to parts and conditions yield from a framework that can be characterized. Connections between them can be addressed through conditions in a numerical model. Imperatives can be brought into the model and activity research strategies of recreation and improvement can be utilized to augment targeting, assess hazards, and so forth. System approach : concern components of above disciplines can best be contemplated to frameworks investigation. Factors portraying contributions to, parts and conditions of, and yields from a framework can be characterized and connections between them can be addressed through conditions in a numerical model.

\section{River water simulations}

The river water simulation has done with the Hecras software to obtain the volume calculation and finally calculated from the given rain fall data from the given year 2020 from august and September month from 6 automatic weather stations. The precipitation data is used in a given tabular column and further, it is used for runoff volume calculation. [1].

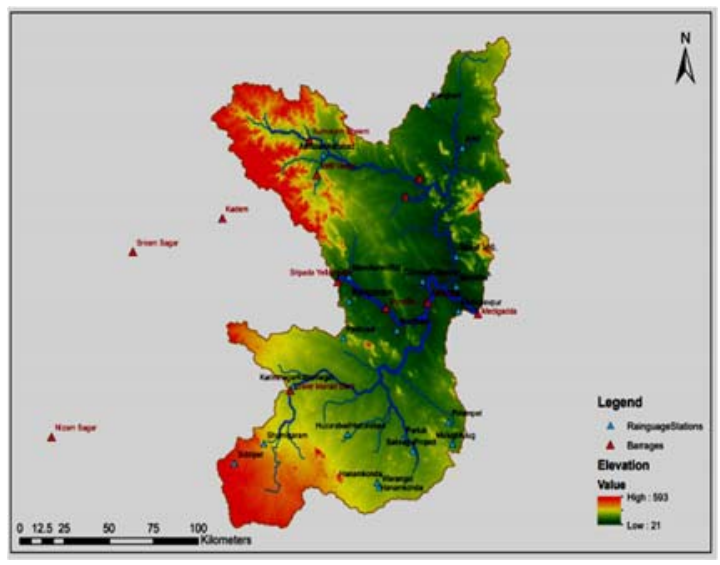

Fig.7 . Showing the thematic map of study area

The study area has Latitude, Longitude are give in the tabular column TAb1. The latitude and longitude are ranging from the $18.710868,18.736386$, and $79.611385,79.825502$. The reservoir locations are Scouring of the bed width and uniform flow computations, etc used in the analysis [2] 


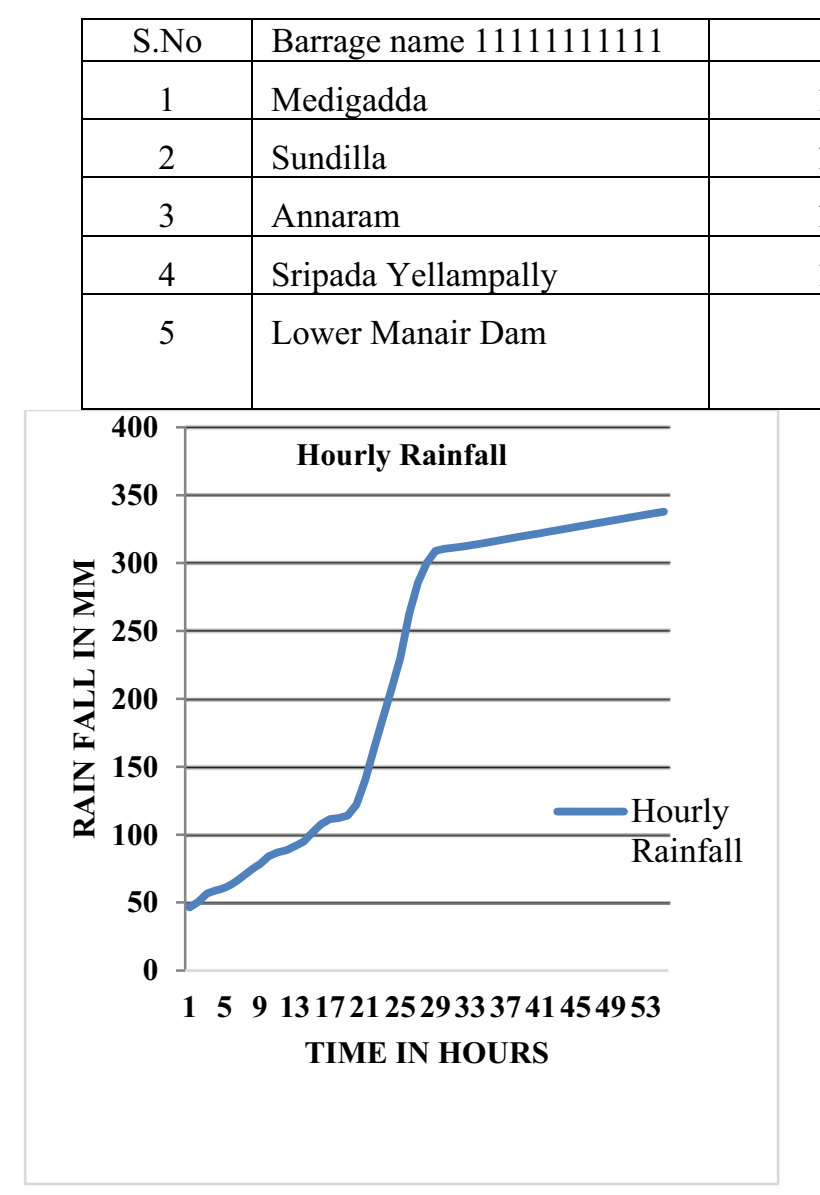

Fig 6. Showing the rain fall and time series
Given in the Table.2. The Medigadda barrage has 18.710868 of latitude and 0.8074451 longitude similarly other barrages like Sundilla, Annaram , Yellampalli other barrages also mentioned in Table2. The climate data used for the study was from 2008 to 2014[3].

The DEM has taken from Bhuvan website ISRO India [4].

Table 2 Barrages location in Study area

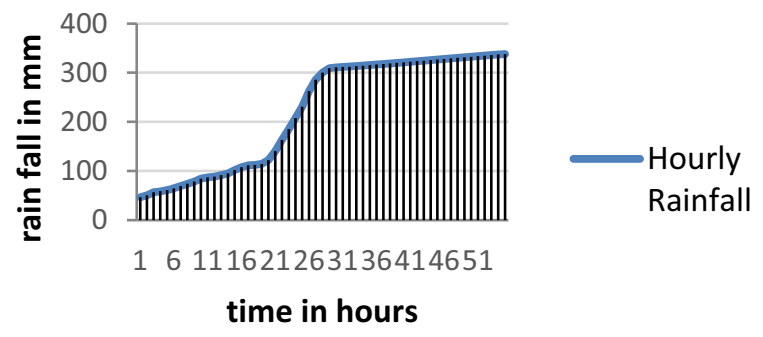




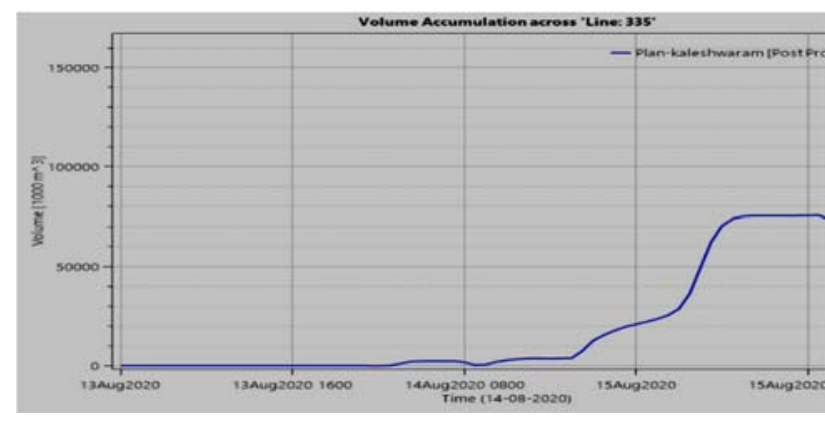

Fig 8 Cumulative rain fall for the simulation

Fig 6 cumulative rain fall for grapg for the taken simulation run

Fig 9 Volume of the river water and time graph

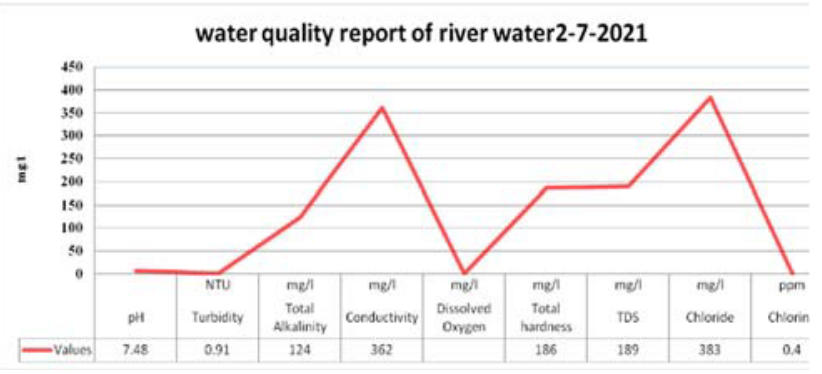

integrated river basin management, collaborative

Table. 2 water qulity reports 2-7-2021

\begin{tabular}{|c|l|c|c|c|}
\hline \multicolumn{2}{|c|}{ Description } & Units & Values & Remarks \\
\hline SI.No & \multicolumn{1}{|c|}{ Date: 02-07-2021 } \\
\hline 1 & pH & & 7.48 & \\
\hline 2 & Turbidity & $\mathrm{NTU}$ & 0.91 & \\
\hline 3 & Total Alkalinity & $\mathrm{mg} / \mathrm{l}$ & 124 & \\
\hline 4 & Conductivity & $\mathrm{mg} / \mathrm{l}$ & 362 & \\
\hline 5 & Dissolved Oxygen & $\mathrm{mg} / \mathrm{l}$ & & \\
\hline 6 & Total hardness & $\mathrm{mg} / \mathrm{l}$ & 186 & \\
\hline 7 & TDS & $\mathrm{mg} / \mathrm{l}$ & 189 & \\
\hline 8 & Chloride & $\mathrm{mg} / \mathrm{l}$ & 383 & \\
\hline 9 & Chlorine & $\mathrm{ppm}$ & 0.4 & \\
\hline
\end{tabular}

Fig 10 water quality report for the river water 2-7-2021.

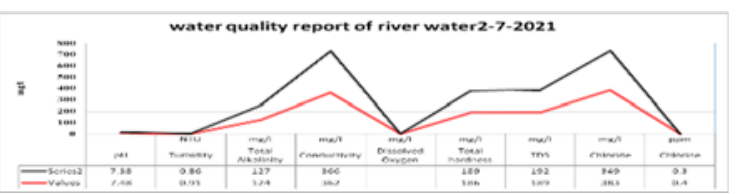

Fig 10 water quality report for the river water 2-7-2021.

And 9-7-2021

Table.3 water qulity reports 9-7-2021

\begin{tabular}{|c|c|c|c|}
\hline Sl.No & Description & Units & Values \\
\hline 1 & $\mathrm{pH}$ & & 7.38 \\
\hline 2 & Turbidity & NTU & 0.86 \\
\hline 3 & Total Alkalinity & $\mathrm{mg} / \mathrm{l}$ & 127 \\
\hline 4 & Conductivity & $\mathrm{mg} / \mathrm{l}$ & 366 \\
\hline 5 & $\begin{array}{l}\text { Dissolved } \\
\text { Oxygen }\end{array}$ & $\mathrm{mg} / \mathrm{l}$ & -- \\
\hline 6 & Total hardness & $\mathrm{mg} / \mathrm{l}$ & 189 \\
\hline 7 & TDS & $\mathrm{mg} / \mathrm{l}$ & 192 \\
\hline 8 & Chloride & $\mathrm{mg} / \mathrm{l}$ & 349 \\
\hline 9 & Chlorine & ppm & 0.3 \\
\hline
\end{tabular}

Figure 8 , is the rainfall and hour graph and it shows the peak rainfall at 7.00 hours of the 15 th morning of August 2020 rainfall. The different times the rainfall is varying the different intensity has recorded. The maximum rainfall occurs at $5 \mathrm{pm}$ in the evening shown in the graph. . The graph is... The graph is generated with simulation software to obtain the Hyetograph.. The Fig. 9 run of volume in the river with simulation rainfall data (for a given date of 158-2020) the maximum rain occur. The rainfall for the given max. The month of august has generated volumes for peak rainfall. The maximum peak volume is $1,50,000 \mathrm{~m}^{3}$ for the august month at 16.00 hours time. The different volumes which are generated by the simulation are 50,000, 10,000 cub. Met. .which are represented for the same month of 13-aug-2020 and 14-Aug-2020 and finally 15-aug2020 it has recorded max values. Table 2 and Table 3 are representing the water quality reports which are related to the $\mathrm{PH}$ value and turbidity, alkalinity, conductivity, dissolved oxygen ( not aplicable), hardness, chlorides and residual chloride. For the river water taken from the latest report.. Fig 10. Especially it is comparing both test values for 2-72021 and 9-7-2021. For the 9-7-2021 the values are a little bit higher than the 2-7-2021 values. According to US clean water act the total suspended solids are identified as conventional pollutant in water[11]. 


\section{Results and Discussion}

The proposed lift irrigation scheme near Kannepally village, Telangana state. India utilizes 4.5 TMC of water from River Godavari to provide irrigation facilities to an area of 18,211 $\mathrm{Ha}$ and also to supply drinking water to enroot villages in the drought-prone areas of Jayashankar Bhupalpally district (previously Karimnagar Dist) which otherwise flows off to the Bay of Bengal. [12].Addressing the river basin issues in an integrated manner to develop adequate and state-of-the-art water policy can be the best way to address water challenges and ensure sustainable and efficient use of water resources. . Overall, the groundwater quality results were compared with IS 10500:2012 (second revision) in all the seasons and the results were observed to be well within the standards.. Overall, the river water quality results were compared with IS 10500:2012 (second revision) in all the seasons and the results were observed to be well within the standards. The volume calculated for the last five seasons and found for the capacity of water inflow every season and thereby allocation of water for the various needs, That needs can be decided by decision-makers. Finally, The decision-makers to take decisions for the supply of drinking water needs and irrigation needs and other purposes such as industrial requirements..Apart from the needs various water losses also involved in the supply system. [13] Such losses have to take in to consideration for estimation of quality and quantity of needs. Addressing the river basin issues in an integrated manner to develop adequate and state-ofthe-art water policy can be the best way to address water challenges and ensure sustainable and efficient use of water resources. Multidisciplinary experience paired with state-of-the-art IT and the ability to create and distribute tailor-made water management mathematical models. Expertise involving knowledge translation, training, and institutional support to build new operational approaches to the problem of balancing water management tasks and sustainable economic and ecological growth. [14] Multidisciplinary experience paired with state-of-theart IT and the ability to create and distribute tailormade water management mathematical models.
1. Rahul et. al, "U F F modelling using remotely sensed data and hec-ras, pune case study", Asian conference on remote sensing at new Delhi, (2017).

2. Azhar Husain, "Flood Modelling by using HEC-RAS", International Journal of Engineering Trends and Technology (IJETT) - Volume 50, (2017).

3. ISRO Bhuvan, "Open data Archive", Indian Geoplatform of Indian Space Research organization.(2020) 4.. W. Allen, M. Kilvington,. Why Involving People is Important: The Forgotten Part of Environmental Information System Management. Proceedings 2nd (MODSS '99), 1-6 August 1999, Brisbane, Australia. (1999)

5. M.R Bauer, J. Randolph,. "Exploring the Characteristics of Collaborative Environmental Decision Making". E D and P Program, Virginia Tech, Blacksburg, VA, (1998)

6.. R. Davis, R. Hirji, a. Environmental Flows: Case Studies.. Water Resources and Environment Technical Note C.2. The World Bank. Washington, D.C. (2003a)

7. Rahmah Elfithri, Rawshan Ara Begum and Mazlin B. Mokhtar,. Instruments for Integrated Water Resources Management in Malaysia,J.A.S.R,8,(12)PP 5599-5607, (2012)

8. GWP-TEC,. Integrated Water Resources Management. Global Water Partnership Technical Committee (TEC) Background Paper No. 4 (www.gwpforum.org).( 2004)

9. GWP-ToolBox, 2003. Sharing Knowledge for Equitable, Efficient and Sustainable Water Resources Management

10 Global Water Partnership ToolBox Integrated Water Resources Management. (www.gwpforum.org).

11. American Public Health Association. "The Standard Methods Examination Water and Wastewater". 20th Editiron. (1998)

12.EIA Report ,KLIS , Irrigation and Cad Department (2019)

13.P . R. Hunter, .; MacDonald, A.M.; Carter, R.C. Water Supply and Health. PLoS Med. 2010, 7, e1000361..(1998)

13. Z. Ding, , Zhai, Y.; Wu, C.; Wu, H.; Lu, Q.; Lin, J.; He, $\mathrm{F}$. Infectious diarrheal disease caused by contaminated well water in Chinese schools: A systematic review and metaanalysis. J. Epidemial., 27,274-281.( 2017)

14. Sunil Kumar ,Director, NWA, CWC, Pune ,report IRBM\& unesco multi-criteria analysis(2012)

15 . A. Jain, S.K.V. Prasad Indurthy,. Carative Analysis of Event-based Rainfall-runoff Modelling TechniquesDeterministic, Statistical, and Artificial Neural Networks, J. H. E., 8: 93-98.( 2003)

\section{References}

